\title{
Realizing Society 5.0 to Face the Industrial Revolution 4.0 and Teacher Education Curriculum Readiness in Indonesia
}

\author{
Ema Aprilisa \\ Bachelor of Education in Biology, Faculty of Mathematics and Natural Sciences, Universitas Negeri Yogyakarta \\ Email: ema.aprilisa@uny.ac.id
}

\begin{abstract}
Educational institutions have to aware about digital transformation, which is immediately responded with the concept of Industrial Revolution 4.0 or Industry 4.0 as a national strategic initiative from the German government through their Ministry of Education and Research. Meanwhile, Japan also formulated the concept of Society 5.0 aims to create a human-centric society in the era of technology and also to tackle some of negative aspects comes with the rapid change. Therefore, educational institutions need to check their curriculum to cope up with the transformation. This research is to conduct an analysis of teacher education program's curriculum, especially Bachelor of Education in Biology, Faculty of Mathematics and Natural Sciences, Universitas Negeri Yogyakarta. The analysis focus on the correlation between Program Learning Outcome (PLO) with the needs of Industrial Revolution 4.0 era and to realize Society 5.0. It is also highlighting the fact that as a future teacher, the college students of the program need some spesific skills. So that one day, they are able to teach with suitable strategy for the era. The results of this study indicate that some PLOs are in accordance with top ten skills demand in 2022 which is considered to be in line with the essential skills to face Industrial Revolution 4.0 and realize Society 5.0. In fact, the top ten skills demand in 2022 is suspected to have been covered by the PLO formula of the curriculum applied by Bachelor of Education in Biology, Faculty of Mathematics and Natural Sciences, Universitas Negeri Yogyakarta. This provides a glimmer of hope for the future of education in Indonesia, but we still emphasizing the need to ensuring every course supports PLO achievement.
\end{abstract}

Keywords: education; curriculum; technology; industry 5.0; industrial revolution 4.0; society 5.0; teacher education curriculum

\section{INTRODUCTION}

Every country in the world uses its own way to deal with changes due to the rapid technological transformation at this time. The way humans use technology and accompanied by advances in the function of technology itself cannot be denied, changed various aspects of human life. The Japanese government realized this situation, then formulated the concept of Society 5.0 which was intended as their national strategy to deal with the era of the Industrial Revolution 4.0. Society 5.0 was initiated by the Japanese government in 2016, contained in the "5th Science and Technology Basic Plan" by the Council for Science, Technology and Innovation and approved by the cabinet in January 2016 (Fukuyama, 2018).

If we look back at human history, there are several stages of society form. Society 1.0 is a group of people who hunt and gather together to live in harmony with nature. Furthermore, Society 2.0 formed groups based on agricultural cultivation, improved organizational systems and nation formation. Then, Society 3.0 is a society that promotes industrialization through the industrial revolution, thus enabling mass production of various kinds of human needs products. Then, Society 4.0 arise by awareness of the added value by connecting intangible assets as an information network. At present, Society 5.0 becomes a continuation of Society 4.0 , aims to form a society centered on human prosperity (Shiroishi et al., 2018).
Not only being triggered by the development of information technology, the movement towards Society 5.0 is also driven by challenges on a global scale, for example the depletion of natural resources, global warming, and terrorism. Therefore, maximizing information technology is absolutely necessary to gain new knowledge and become more valuable by creating connections between people and things, also between the real and cyber. It must be taken to overcome problems in society, create a better life for humans and maintain healthy economic growth.

The aim of Society 5.0 is to create a human-centered society. To achieve economic development and community challenge resolution, people also can enjoy a high quality of life actively and comfortably, become the main goals. Society 5.0 ensures that everyone gets their needs, regardless of region, age, gender, language and other obstacles, by providing the necessary goods and services. The key to the realization of this goal is the combination of cyber and the real (physical) to produce quality data, so that new solutions can be formulated to solve any challenges in society (Fukuyama, 2018).

Although Society 5.0 is a national strategy by Japanese, this concept is actually can apply globally, because the aim is the same as "Sustainable Development Goals (SDGs)". SDGs or Sustainable Development Goals are seventeen goals with 169 measurable achievements and deadlines set by the United Nations as a development agenda for the benefit of humans and planet earth (Stibbe, et al., 2019). 
Moreover, the challenges in Japan, such as an aging population, declining birth rates, declining population and aging infrastructure, are challenges that will ultimately be faced by many other countries, including Indonesia. As a developing country with a high number of population, a decrease in birth rates and population may not be a problem yet. However, digital transformation that is also experienced in Indonesia, is a door for various new problems, such as increasing social complexity, security risks, and privacy issues.

Therefore, it is necessary to know the readiness in education to face the Industrial Revolution 4.0 and to realize Society 5.0. This paper will present a review of curriculum implemented in the Bachelor of Education in Biology, Faculty of Mathematics and Natural Sciences, Universitas Negeri Yogyakarta. Researchers will examine the compatibility of the program learning outcome with the needs of college students to face the Industrial Revolution 4.0, realize Society 5.0, as well as prospective teachers, so that one day they are able to carry out learning in accordance with the demands in the digital transformation era.

\section{MATERIALS AND METHODS}

This research is a qualitative research. Data was collected by analyzing the curriculum applied by the Bachelor of Education in Biology, Faculty of Mathematics and Natural Sciences, Universitas Negeri Yogyakarta, specifically comparing the program learning outcome which is a benchmark for determining course learning outcomes, with projected skills requirements that become trending or classified in the top ten types of skills needed by 2022 according to the Future of Jobs Report 2018 by the World Economic Forum. This method is carried out to determine the readiness of the education sector, especially the education of prospective teachers in Indonesia to realizing Society 5.0 and to deal with the Industrial Revolution 5.0, especially in the Bachelor of Education in Biology, Faculty of Mathematics and Natural Sciences, Universitas Negeri Yogyakarta.

\section{RESULTS AND DISCUSSION}

\section{Curriculum Applied in the Bachelor of Education in Biology, Faculty of Mathematics and Natural Sciences, Universitas Negeri Yogyakarta}

Bachelor of Education in Biology, Faculty of Mathematics and Natural Sciences, Universitas Negeri Yogyakarta uses the 2014 curriculum which has been revised in 2017. It consists of 144 university credit unit which are grouped into mandatory and elective courses. Subjects that must be taken by undergraduate students in Bachelor of Education in Biology, Faculty of
Mathematics and Natural Sciences, Universitas Negeri Yogyakarta are as many as 134 university credit unit and 10 university credit unit elective courses, selected from 79 university credit unit provided according to the specialization group.

The curriculum was compiled by referring to the vision and mission of the study program, and based on Presidential Regulation No. 8/2012 on the Indonesian National Qualification Framework (KKNI), Minister of Research and Technology Regulations No 44/2015 on Higher Education National Standards (SNPT), and also suggestions from various parties involved, such as the government, organizations engaged in research and education, alumni, and alumni users.

The curriculum is structured in accordance with the program objective of the Bachelor of Education in Biology, Faculty of Mathematics and Natural Sciences, Universitas Negeri Yogyakarta, as follows.

1. Have the competencies to be omid-term examinationtanding, creative, and innovative prospective High School Biology teachers/educators who uphold the pious, independent, and intellectual values.

2. Be able to conduct research that contribute to solving the problems in the biology education, especially through the development of local wisdom-based learning resources.

3. Possess entrepreneurial insight and competency whether independently or with others in the field of biology education that are able to contribute to the surrounding community in an accountable, credible, and transparent manner.

The program objective of Bachelor of Education in Biology, Faculty of Mathematics and Natural Sciences, Universitas Negeri Yogyakarta then described in the form of a program learning outcome. The program learning outcomes aims for the graduates to:

1. Being pious to God Almighty and upholding humanity values in conducting the duties.

2. Having the attitudes with society, nation, and state values with the foundation of Pancasila.

3. Demonstrating responsibility, independence, entrepreneurship, and adaptation in conducting the duties.

4. Mastering basic biology and other relevant knowledge with mathematics and natural sciences.

5. Understanding the principles of TPACK (Technological Pedagogical and Content Knowledge) in biology learning.

6. Mastering the use of information and communication technology in biology learning.

7. Being able to do independent laboratory work and fieldwork.

8. Being able to plan, implement, assess, and follow up the educational biology learning. 
9. Mastering the research methods in biology education as well as its applications.

10. Being able to communicate and collaborate well both verbally and non-verbally.

11.Possessing managerial skill of the profession. Improving the professional expertise through training, work experience or sustainable education.

Every lecturer in the teaching team then sets course learning outcomes based on the program learning outcome. Each team also designs lesson plan that are considered most appropriate to ensure the achievement of course learning outcome. The lesson plan is written in the document that contains at least the subject or concept and skills that must be mastered by students, appropriate lesson activities to support each mastery of concepts and skills along with the time required, assessment indicators, and assessment techniques.
The Correlation of Future Skills Formulated in the Future of Jobs Report 2018 by the World Economic Forum with the Industrial Revolution 4.0 and Society 5.0

The Future of Jobs Report 2018 by the World Economic Forum was prepared to provide specific information about trends in the industry, related to employment and skills, in various countries. This is seen as important in connection with the Industrial Revolution 4.0 which is predicted to cause major changes in the labor market. New job categories will emerge and some will replace the types of jobs that are not needed anymore in the future, both by industry and society. According to the Future of Jobs Report 2018, there will be a change in skills requirements by 2022 . The following are the ten main skills most needed in 2018, compared to later in 2022 , along with a list of skills that are likely to be increasingly unnecessary in 2022.

Table 1. Most Needed Skills according to the Future of Jobs Report 2018 by the World Economic Forum.

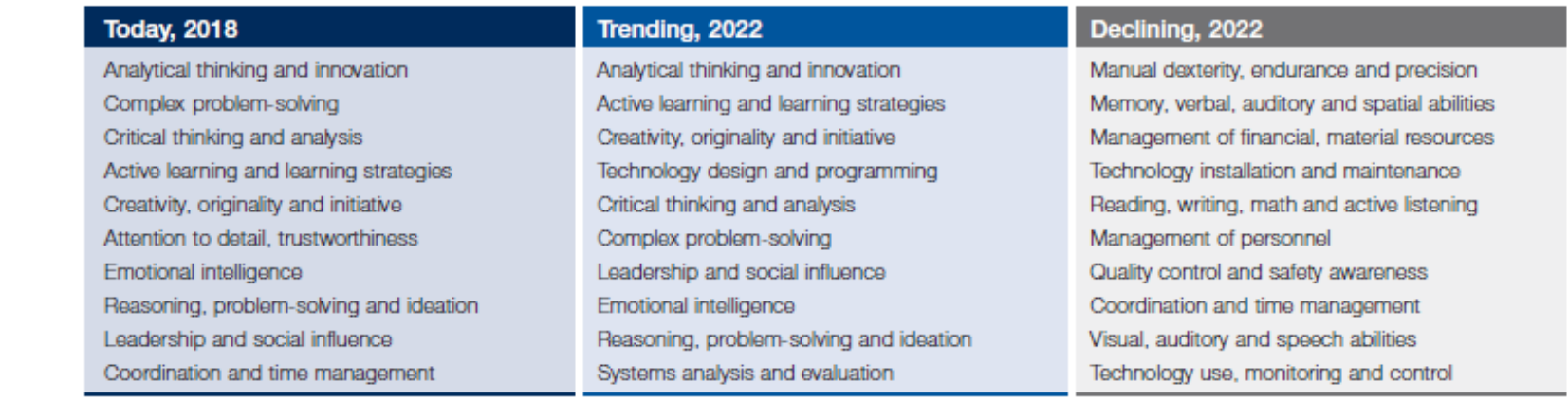

Source: (World Economic Forum, 2018)

Those skills are also important for realizing Society 5.0 which is a response to world technological advances in the Industrial Revolution 4.0. The goal of achieving Society 5.0 is also in accordance with "Sustainable Development Goals (SDGs)" (Fukuyama, 2018). SDGs or Sustainable Development Goals are seventeen goals with 169 measurable achievements and deadlines set by the United Nations as a development agenda for the benefit of humans and planet earth. These objectives are, (1) to create a world without poverty, (2) ending hunger by realizing food security and improving nutrition through sustainable agricultural systems, (3) creating healthy and prosperous life, promoting healthy living and supporting welfare for all ages, (4) providing decent and inclusive quality education, and encouraging lifelong learning opportunities for everyone, (5) gender equality and empowering all women, (6) ensuring access to clean water and sanitation, (7) ensuring access to clean energy that is affordable, reliable, sustainable and modern, (8) decent work and economic growth, (9) build strong infrastructure, promote sustainable industrialization and encourage innovation, (10) reduce inequalities within and between countries, (11) make inclusive, safe, strong, and sustainable urban areas, (12) ensuring sustainable consumption and production patterns, (13) melak This is an important step to combat climate change and its impacts, (14) Protect and use oceans, oceans and marine resources in a sustainable manner, (15) manage forests sustainably, fight land conversion to desert, stop and rehabilitate land damage, stop biodiversity extinction, (16) encourage a just, peaceful and inclusive society, and (17) revive global partnerships for sustainable development (United Nations, 2015).

\section{The Compatibility of the Program Learning Outcome with the Future Skills in Industrial Revolution 4.0 and Society 5.0}

According to the list of the most needed skills according to the Future of Jobs Report 2018 by the World Economic Forum as shown in Table 1, there are ten skills that are predicted to be trending by 2022, as follows.

1. Analytical thinking and innovation.

Have ability to analyze information and using logic to address work-related issues and problems. 
Innovation means creativity and alternative thinking to develop new ideas for and answers to work-related problems.

2. Active learning and learning strategies.

Understanding the implications of new information for both current and future problem-solving and decision-making. Meanwhile, learning strategies means that they have ability to choose and using training or instructional methods and procedures appropriate for the situation when learning or teaching new things.

3. Creativity, originality and initiative.

Creativity relate to try out their own ideas, originality refer to the ability to come up with unusual or clever ideas about a given topic or situation, or to develop creative ways to solve a problem, and initiative mean a willingness to take on responsibilities and challenges.

4. Technology design and programming.

Technology design is a ability to generating or adapting equipment and technology to serve user needs. While programming is writing computer programs for various purposes.

5. Critical thinking.

Using logic and reasoning to identify the strengths and weaknesses of alternative solutions, conclusions or approaches to problems.

6. Complex problem-solving.

Identifying complex problems and reviewing related information to develop and evaluate options and implement solutions.

7. Leadership and social influence.

Leadership is a willingness to lead, take charge, and offer opinions and direction. Social influence is a skill to having an impact on others in the organization, by displaying energy and leadership.

8. Emotional intelligence.

It has several aspects, first is concern for others. Being sensitive to others' needs and feelings, also being understanding and helpful are predicted become important skill for the future. Cooperation mean being pleasant with others and displaying a good-natured and cooperative attitude, also become part of emotional intelligence. Two other aspects are social orientation and social perceptiveness. Preferring to work with others rather than alone, being personally connected with others on the job, and being aware of others' reactions and understanding why they react as they do are the intention of social orientation and social perceptiveness.

9. Reasoning, problem-solving and ideation.

Reasoning and ideation are abilities that influence the application and manipulation of information in problem-solving.
10. Systems analysis and evaluation.

Systems analysis is determining how a system should work and how changes in conditions, operations, and the environment will affect outcomes. Meanwhile, systems evaluation is identifying measures or indicators of system performance and the actions needed to improve or correct performance, relative to the goals of the system.

All of that skills listed is tried to achieve in Bachelor of Education in Biology, Faculty of Mathematics and Natural Sciences, Universitas Negeri Yogyakarta. The following is the description of the compatibility between ten skills that are predicted to be trending by 2022 according to the Future of Jobs Report 2018 by the World Economic Forum with the program learning outcomes.

1. Analytical thinking and innovation.

This skill is in accordance with program learning outcome point 3, "demonstrating responsibility, independence, entrepreneurship, and adaptation in conducting the duties". The skills of innovation in accordance with the program learning outcome, especially at the point of adaptation in conducting the duties. PLO point 9 namely "mastering the research methods in biology education as well as its applications" is also compatible with the analytical thinking skill because the students need to have the skill to complete the program learning outcome.

2. Active learning and learning strategies.

Conduct active learning with personal awareness, implicit in several program learning outcomes. Especially in PLO 7 and 8. In PLO 7, students are expected to be able to do laboratory work and fieldwork independently. Whereas in PLO 8, students are expected to be able to plan, implement, assess, and follow up the educational biology learning. Both are considered compatible with active learning skills, understanding the implications of new information for both current and future problem-solving and decision-making. Also learning strategies skills that they have the ability to choose and use training or instructional methods and procedures appropriate for the situation when learning or teaching new things.

3. Creativity, originality and initiative.

These three skills compatible with several program learning outcomes. Program learning outcomes point 8 for instance, obliging students to be able to plan, implement, assess, and follow up the educational biology learning implies that students must be able to plan creative learning and come up with original ideas. Whereas program learning outcomes point 11, possessing managerial skill of the profession, ensuring students to achieve initiatives skill, to take on responsibilities and challenges. 
4. Technology design and programming.

The skills are specifically related to program learning outcome point 6 , "mastering the use of information and communication technology in biology learning". Some courses have involved activities to practice the ability of students to not only use learning media, but also to create appropriate learning media. However, programming is not specifically taught in the course.

5. Critical thinking and analysis.

Using logic and reasoning to identify the strengths and weaknesses of alternative solutions, conclusions or approaches to problems are not specifically mentioned in the program learning outcomes, but their achievements on the skills will be seen in the course outcome and in the indicators of achievement of each course.

6. Complex problem-solving.

As with critical thinking and analysis skills, there is no specific program learning outcomes that mentions this skill. But in the point 7 of the program learning outcomes, states that graduates must be able to do independent laboratory work and fieldwork, complex problem-solving is clearly needed. So it is assumed, if the student has reached the program learning outcomes, he has mastered complex problem-solving skills.

7. Leadership and social influence.

The skills to be a leader have been specifically mentioned in point 3 of the program learning outcomes. It is explicitly mentions the importance of demonstrating responsibility in conducting the duties. In addition, program learning oucomes point 11 also mentioned about possessing managerial skills of the profession. This is also in accordance with the achievement of social influence skills. Skill to have an impact on others in the organization, by displaying energy and leadership is also in accordance with the achievement of the program learning outcomes point 10 , "being able to communicate and collaborate well both verbally and non-verbally".

8. Emotional intelligence.

This skill is in accordance with point 1 and 2 of program learning outcomes. Point 1 mentions explicitly about upholding humanity values in conducting the duties. While in point 2 , it is also stated that the students must have the attitudes with society, nation, and state values.

9. Reasoning, problem-solving and ideation.

It is not specifically mentioned in the program learning outcomes, but its achievement will be seen in the course outcome, especially in the indicators of each course.

10. Systems analysis and evaluation.

Students must understand how a system should work and how changes in conditions, operations, and the environment will affect outcomes. This is shown in point 7 of program learning outcomes, "being able to do independent laboratory work and fieldwork", also in point 8 , "being able to plan, implement, assess, and follow up on educational biology learning", and point 9, "mastering the research methods in biology education as well as its applications". In point 8 , it also mentions the skills of evaluation to identify measures or indicators of system performance and actions needed to improve or correct performance, relative to the goals of the system.

Based on the compatibility analysis, it can be concluded that every skill that are predicted to be trending by 2022 according to the Future of Jobs Report 2018 by the World Economic Forum has also been determined by Bachelor of Education in Biology, Faculty of Mathematics and Natural Sciences, Universitas Negeri Yogyakarta as program learning outcomes. In other words, the determination of program learning outcomes is in accordance with the most needed skills in the future. The results of this analysis are indeed still too shallow because they have not reviewed up to the level of course learning outcomes which are certainly more detailed.

Nonetheless, the results have provided the view that the education of prospective teachers in Indonesia, particularly in the Bachelor of Education in Biology, Faculty of Mathematics and Natural Sciences, Universitas Negeri Yogyakarta has required mastery of skills that are essential for facing the Industrial Revolution 4.0 and Society 5.0. It should be reiterated that the third and fourth industrial revolutions relate primarily to Information and Communication Technologies (ICT). The third industrial revolution used ICT for automatic control of production machinery, meanwhile the upcoming Industrial Revolution 4.0 takes this to a qualitatively new level, which is characterized by machine to machine communication, without involving the role of humans in the decision making process (Hartmann and Bovenschulte, 2013).

The role of humans has re-emerged in the concept of Society 5.0. People with future skills are expected to be able to design systems to overcome problems in society, create a better life, and maintain healthy economic growth. Thus, everyone is expected to enjoy a quality life. According to the concept of Society 5.0, this previllage can be enjoyed by all people, from all regions, ages, genders, languages, without any restrictions that are now still become obstacles.

\section{REFERENCES}

Fukuyama, Mayumi. 2018. Society 5.0: Aiming for a New Human-centered Society. Japan Spotlight. https://www.jef.or.jp/journal/

Hartmann and Bovenschulte. 2013. Skills Needs Analysis for Industry 4.0 Based on Roadmaps for Smart Systems. SKOLKOVO Moscow School of Management \& International Labour Organization (ed.) (2013): Using Technology 
Foresights for Identifying Future Skills Needs. Global Workshop Proceedings, Moscow

Shiroishi, K. Uchiyama, and N. Suzuki. Society 5.0: For Human Security and Well-Being. Computer 51 (7), 91-95. doi: 10.1109/MC.2018.3011041

Program Studi Pendidikan Biologi FMIPA UNY. Program Objective and Program Learning Outcome. http://pendbiologi.fmipa.uny.ac.id

Program Studi Pendidikan Biologi FMIPA UNY. Curriculum. http://pend-biologi.fmipa.uny.ac.id
Stibbe, Darian, Stuart Reid, Julia Gilbert. 2019. Maximising the Impact of Partnerships for the SDGs. https://sustainabledevelopment.un.org

United Nations. 2015. Transforming our World: The 2030 Agenda for Sustainable Development. https://sustainabledevelopment.un.org

World Economic Forum. 2018. The Future of Jobs Report. http://www3.weforum.org 